Review

\title{
A systematic literature review of diabetes self-management education features to improve diabetes education in women of Black African/Caribbean and Hispanic/ Latin American ethnicity
}

\author{
Enza Gucciardi a,*, Vivian Wing-Sheung Chan ${ }^{\mathrm{b}}$, Lisa Manuel ${ }^{\mathrm{a}}$, Souraya Sidani ${ }^{\mathrm{c}}$

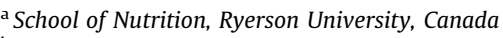 \\ ${ }^{\mathrm{b}}$ Department of Psychology, University of Waterloo, Canada \\ ${ }^{\mathrm{c}}$ Daphe Cockwell School of Nursing, Ryerson University, Canada
}

\section{A R T I C L E I N F O}

\section{Article history:}

Received 23 August 2012

Received in revised form 1 February 2013

Accepted 9 March 2013

\section{Keywords:}

Diabetes self-management education

Patient education

Ethnic groups

Women

\begin{abstract}
A B S T R A C T
Objective: This systematic literature review aims to identify diabetes self-management education (DSME) features to improve diabetes education for Black African/Caribbean and Hispanic/Latin American women with Type 2 diabetes mellitus.

Methods: We conducted a literature search in six health databases for randomized controlled trials and comparative studies. Success rates of intervention features were calculated based on effectiveness in improving glycosolated hemoglobin (HbA1c), anthropometrics, physical activity, or diet outcomes. Calculations of rate differences assessed whether an intervention feature positively or negatively affected an outcome.

Results: From 13 studies included in our analysis, we identified 38 intervention features in relation to their success with an outcome. Five intervention features had positive rate differences across at least three outcomes: hospital-based interventions, group interventions, the use of situational problemsolving, frequent sessions, and incorporating dietitians as interventionists. Six intervention features had high positive rate differences (i.e. $\geq 50 \%$ ) on specific outcomes.

Conclusion: Different DSME intervention features may influence broad and specific self-management outcomes for women of African/Caribbean and Hispanic/Latin ethnicity.

Practical implications: With the emphasis on patient-centered care, patients and care providers can consider options based on DSME intervention features for its broad and specific impact on outcomes to potentially make programming more effective.
\end{abstract}

(C) 2013 Elsevier Ireland Ltd. Open access under CC BY-NC-ND license.

\section{Introduction}

The North American prevalence of diabetes mellitus (DM) reached $10.2 \%$ in 2010 , and is estimated to reach $12.1 \%$ by 2030 . This is an increase of $42.4 \%$ in the number of adults who will have diabetes [1]. There is a growing ethnic disparity in the prevalence of diabetes and its related complications. In the United States, the 2004/06 national survey data indicated that the prevalence of diabetes was greater in non-Hispanic Blacks (11.8\%) and Hispanics (10.4\%) compared to non-Hispanic whites (6.6\%) [2]. In Ontario, the most populated province in Canada, the Black population has higher rates of diabetes (11.6\%) than the White population (7.3\%) [3]. Furthermore, recent immigrants from Latin America and the

\footnotetext{
* Corresponding author at: School of Nutrition, Ryerson University, 350 Victoria Street, Toronto, Ontario M5B 2K3, Canada. Tel.: +1 416979 5000x2728; fax: +1 4169795204 .

E-mail address: egucciar@ryerson.ca (E. Gucciardi).
}

Caribbean (9.8\%) have the second highest prevalence rates of diabetes compared with long-term residents and recent Western Europe and North America immigrants (5.2\%) in Ontario [4]. Overall, North America has a growing ethnic population at an elevated risk of developing diabetes.

In addition to high prevalence rates, persons of Hispanic/Latin and African/Caribbean backgrounds in North America are at higher risk for poor glycemic control and diabetes-related complications. Non-Hispanic Blacks with diabetes have poorer glycemic control, higher blood pressure, and a higher risk of diabetes complications compared with non-Hispanic Whites and Mexican Americans [5]. For instance, Latin Americans and African Americans tend to have substantially higher mean glycosolated hemoglobin (HbA1c) levels than Caucasians [6], and accordingly are at a higher risk of complications such as coronary heart disease [6], retinopathy [7], end-stage renal disease $[7,8]$ and death $[6,8]$.

Although certain ethnic minorities are vulnerable to developing diabetes and related complications, the risks appear to be higher in women than men. African/Caribbean and Hispanic/Latin American 
immigrant women in Ontario have higher rates of diabetes compared with men from the same country [4]. Research shows that women living with diabetes may be at higher risk for developing cardiovascular disease (CVD) $[9,10]$ than men, and that mortality from both coronary heart disease [11,12] and stroke [13] is greater in women than men with diabetes. The prevalence of mental illness such as depression and anxiety disorders is also greater in women compared to men living with diabetes $[14,15]$. The impact of these disorders adversely affects self-care behaviours, glycemic control, quality of life, and diabetes complications [14-17]. The greater risk of complications in women compared to men may be due to differences in how women experience and manage their diabetes.

While it is well established that diabetes self-management education (DSME), a complex health intervention, is generally effective at enhancing self-care behaviors [18-21], improving glycemic control [22], lowering health care costs [23], and improving quality of life $[18,20]$, the specific impact of DSME features on outcomes have not been thoroughly evaluated [24] particularly for specific cultural and gendered populations. For instance, research shows that women have different self-management education needs compared with men. Latin American women are said to be better suited to and more successful with interventions that incorporate family, peers, and promotoras (i.e., community health workers) for social support [25]. South Asian women find it harder than men to discuss their problems with male physicians or to participate in mixed-gender education groups [26]. These findings suggest that men and women with diabetes may have different DSME needs and that different cultures may respond better to various DSME intervention features than others. A better understanding of which intervention features are associated with improved outcomes by gender and culture can be used to target interventions to specific populations to enhance learning, skills building, and diabetes management more effectively than a standardized DSME program.

Given the rising prevalence of diabetes among women from certain ethnic backgrounds and women's greater risk of diabetes complications compared with men, the goal of our study was to systematically review the literature to identify DSME features associated with various self-management outcomes. For women of African/Caribbean or Hispanic/Latin ethnicity living in industrialized countries. The impetus for our research was to help direct the development of a new government-funded DSME program at a community health center specifically tailored for women from high-risk ethnic groups for diabetes. The results from this study are intended to help diabetes educators and health practitioners learn how best to deliver DSME to achieve the desired self-management outcomes.

\section{Methods}

\subsection{Search strategy}

Key words used to search for relevant articles included: adult, Type 2 DM, patient care management, patient education, patientcentered care, ethnic groups, and competency-based education. A library technician searched for relevant articles published in English from 1980 to 2008 in Medline, Embase, Cinahl, Cochrane Library, HealthStar, PsycInfo, and ProQuest Nursing \& Alliance Health. Using women as a key search term was not recommended due to the high probably of excluding studies that sampled primarily women. Thus, the search strategy was broad (sensitive) to include as many relevant articles through subsequent manual screening. Reference lists of relevant reviews and articles and tables of contents from Diabetes Care and Diabetes Educator were thoroughly reviewed to ensure all relevant studies were obtained. Lastly, researchers in the field were contacted to identify relevant gray literature; however, no new resources were identified.

\subsection{Inclusion criteria}

Studies were limited to randomized controlled trials and comparative studies. Primary studies that provided outcomes of DSME interventions initially for three ethnic groups (i.e., African/ Caribbean, Hispanic/Latin and South Asian women) in industrialized countries were reviewed. Articles had to focus on participants diagnosed with Type 2 DM who were over 18 years of age. Given the few numbers of diabetes self-management interventions conducted exclusively with Black African/Caribbean and Hispanic/Latin American women with Type 2 DM, we included studies that had a sample of a minimum of $70 \%$ women (representing the majority of the samples) or reported analyses by sex. Studies were excluded if the articles were not peerreviewed and did not provide enough information about the type of program to analyze the intervention's features. Lastly, we excluded articles that focused solely on groups of subjects with a specific co-morbidity (e.g., those only with heart disease, kidney disease, stroke, etc.), and reports of intervention feasibility. We were also unable to find studies for South Asian women (as stipulated in the inclusion and exclusion criteria) and thus unable to include this population of women in the review. Fig. 1 shows the selection process of this review.

\begin{tabular}{|c|c|}
\hline \multicolumn{2}{|l|}{$\begin{array}{l}\text { Initial citation lists from all } \\
\text { databases by key words }(n=9,019)\end{array}$} \\
\hline $\begin{array}{l}(\mathrm{n}=8,583 \text { excl } \\
\text { primary interve } \\
\text { key terms of in }\end{array}$ & $\begin{array}{l}\text { uded: no abstract, not } \\
\text { ntion articles, not fitting } \\
\text { clusion criteria) }\end{array}$ \\
\hline \multicolumn{2}{|l|}{$\begin{array}{l}\text { Initial screening of citations by } \\
\text { reviewers }(n=436)\end{array}$} \\
\hline $\begin{array}{l}(\mathrm{n}=\mathbf{3 8 2} \text { exclu } \\
\text { not of target } \mathrm{p}\end{array}$ & $\begin{array}{l}\text { led: not Type } 2 \text { DiM } \\
\text { pulation age) }\end{array}$ \\
\hline $\begin{array}{l}\text { Secondary screening by reviewers } \\
\text { from abstracts }(\mathrm{n}=\underline{\mathbf{5 4}})\end{array}$ & \\
\hline
\end{tabular}

( $n=\mathbf{3 8}$ excluded: did not report any between-group outcomes or not female specific, exploratory study/pilot study primarily reporting development or feasibility of intervention, secondary analysis insufficient data in article for data extraction, not targeted at cultural group of interest)

$\begin{aligned} & \text { Full text articles that met the } \\ & \text { inclusion criteria }(\mathrm{n}=\mathbf{1 6})\end{aligned}$
\[ \begin{array}{l}(\mathrm{n}=3 \text { excluded: did not report } \\ \text { outcomes of interest })\end{array} \]
$\begin{aligned} & \text { Full text articles that were } \\ & \text { analyzed }(\mathrm{n}=\mathbf{1 3})\end{aligned}$
Fig. 1. Selection process of studies based on search strategy (1980-2008).

Fig. 1. Selection process of studies based on search strategy (1980-2008). 


\subsection{Data extraction}

Abstracts were independently screened by two of the authors (L.M. and V.C.) to determine eligibility for inclusion in the review. After the authors (L.M. and V.C.) retrieved eligible articles, each author was responsible for extracting half of the articles. A data extraction form was adapted from the literature $[27,28]$ for this purpose. Following data extraction, the two authors exchanged articles, read them, and reviewed the corresponding data extraction sheet performed by the other person to ensure data extraction accuracy. There were few discrepancies between the two reviewers in the extracted data that were resolved in consensus discussion with the lead author (E.G.).

This review examined the following intervention features of DSME: (i) intervention setting, (ii) intervention format, (iii) mode of delivery, (iv) education strategies, ( $v$ ) duration-length of intervention, (vi) intensity-frequency of session, (vii) type of interventionist, (viii) content delivered to the participants, and (ix) intervention design (Table 2).

\subsection{Validity assessment}

Quality assessment $[29,30]$ was conducted by two of the authors (L.M. and V.C.) to review the clarity of the study aims, the adequacy of details about the sample, the rating of the study design, the clarity of the methodology, and the reliability and validity of the measures and tools. Scores were allocated based on the presence of potential bias in these components as reported in the articles. The accumulated score was divided by the number of components in the scoring for the quality of the studies. A study with a final score of $75 \%$ or more was considered "good quality", between 51 and 74\% "fair", and a 50\% or less "poor".

\subsection{Data analysis}

Due to the heterogeneity of populations, interventions, and measured outcomes, we could not conduct a meta-analysis. We therefore used a recently described method to identify specific intervention features likely to be associated successfully or unsuccessfully with the outcome of interest [31]. Interventions were analyzed based on their success in producing a significant change ( $p$-value $\leq 0.05$ ) in outcomes, in the hypothesized direction [31]. Outcome measures of interest were HbA1c levels, anthropometrics, physical activity, and diet outcomes. Studies that reported at least one of the four outcomes were included in the analysis. These four outcomes were selected based on what most studies investigated, although instruments measuring these outcomes varied across studies. For instance, anthropometrics consisted of various measures including body mass index, thigh skinfold, body weight, tricep skinfold, waist-to-hip ratio, total body fat, percent body fat, trunk fat, and fat-free mass. Diet was assessed with a desirable change in any of the following: total kilocalorie intake, dietary risk score, mean vegetable consumption, fruit consumption, consumption of five fruits and vegetables per day, fried food consumption, healthy eating plan adherence, fat-related dietary habits, dietary fat intake, dietary cholesterol intake, kilocalories from saturated fat, and percent kilocalories from fat. When a study used several instruments to measure an outcome (e.g., diet), at least 60\% (an arbitrary cut-off) of the measures must have reported significant positive results to be considered a success for that outcome. Only post-test outcome data were used for all analysis.

A rate difference determines which intervention feature has a positive or negative association with an outcome [31]. A rate difference was estimated for each intervention feature identified in the review using the following steps. First, a success rate was calculated for both the intervention with and without the feature. The success rate for the intervention feature (SRWF) is the number of studies reporting on the intervention having the feature of interest associated with a positive participant outcome, divided by all the studies reporting on intervention with the feature regardless of outcome; the specific formula used was: number of studies with feature with positive outcome/all studies with feature. Second, a success rate without a feature (SRWoF) is the number of studies reporting on the intervention without the feature of interest with a positive participant outcome, divided by all the studies without the feature regardless of outcome; the formula was: number of studies without feature with positive outcome/all studies without the feature. Third, rate differences were calculated for each intervention feature, by subtracting the success rate with feature (SRWF) from the success rate without the feature (SRWoF). The higher a positive rate difference the more likely that feature has a successful association on the outcome.

As an example, the following explains how the rate difference of $66.67 \%$ for the intervention feature related to setting of intervention delivery (i.e., home-based) on diet outcomes was calculated in Table 2. Three out of six studies reported an intervention with a home-based setting and three studies did not. Two out of three studies indicated a positive effect of the intervention with the feature on diet outcome and none of the three studies without the feature found a positive effect on diet outcome; accordingly, the rate difference was: SRWF $-\mathrm{SRWoF}=(2 / 3)-(0 / 3)=66.67 \%$. Since this number is positive, the results suggest that the feature of home-based setting had a positive association with diet outcomes. The higher a positive rate difference the more likely that feature has a successful association on the outcome.

\section{Results}

\subsection{Description of studies}

Thirteen studies were analyzed. Study characteristics can be found in Table 1 . Ten articles $[19,32-40]$ were randomized controlled trials; the remaining three [41-43] were cohort studies including both an intervention group and a comparison group. Eight studies included African/Caribbean American [19,32,33, 36,38,41-43] participants. Three studies [37,39,40] included mixed cultural groups composed mainly of African American and some Caucasian participants. Two of the studies had Hispanic/ Latin American participants [34,35]. Five articles had exclusively women participants $[38-40,42,43]$. One study had sex-stratified results (but the sample was also comprised of more than $70 \%$ women [35]). The remaining studies had at least $70 \%$ women participants [19,32-34,36,37,41]. With regards to quality, only one article received a rating of "Fair" [43], all other articles were rated as "Good" (see Table 1). Because only 13 studies met our inclusion criteria, we were unable to stratify our analysis by ethnic group as originally planned.

\subsection{Analysis of features}

Table 2 displays the intervention features that have positive success rate differences for HbA1c, anthropometrics, physical activity, and diet outcomes.

\subsection{HbA1c levels}

Ten studies reported on HbA1c levels [19,32-34,36,38-42]; three of these studies $[32,36,39]$ indicated positive effects. A total of 37 intervention features were included in this analysis, of which 18 were associated with a positive success rate difference (see Table 2). 
Summary table of reviewed articles.

\begin{tabular}{|c|c|c|c|c|c|c|}
\hline Author(s) & Cultural group & Theoretical basis & Study objective(s) & Study design & Setting & Interventionist(s) \\
\hline $\begin{array}{l}\text { Agurs-Collins } \\
\text { et al. [32] }\end{array}$ & $100 \%$ African American & Social Action Theory. & $\begin{array}{l}\text { To evaluate a weight loss and } \\
\text { exercise program designed to } \\
\text { improve diabetes management. }\end{array}$ & $\begin{array}{l}\text { Randomized Control Trial } \\
\text { (RCT). }\end{array}$ & $\begin{array}{l}\text { Urban hospital in } \\
\text { Washington, DC. }\end{array}$ & $\begin{array}{l}\text { A nurse and exercise } \\
\text { physiologist. }\end{array}$ \\
\hline Anderson [41] & 96\% African American & $\begin{array}{l}\text { Empowerment } \\
\text { Behavior Change } \\
\text { Model. }\end{array}$ & $\begin{array}{l}\text { To explore the impact of a } \\
\text { problem-based empowerment } \\
\text { intervention. }\end{array}$ & $\begin{array}{l}\text { Randomized Control Group } \\
\text { Pre-test/post-test Design. }\end{array}$ & Community of Detroit. & $\begin{array}{l}\text { A nurse and a dietician who } \\
\text { are certified diabetes } \\
\text { educators. }\end{array}$ \\
\hline $\begin{array}{l}\text { Anderson-Loftin } \\
\text { et al. [33] }\end{array}$ & $100 \%$ Black African & None. & $\begin{array}{l}\text { To test the effects of a culturally } \\
\text { competent dietary self- } \\
\text { management intervention on } \\
\text { physiological outcomes and } \\
\text { dietary behaviors. }\end{array}$ & RCT. & $\begin{array}{l}\text { Diabetes education } \\
\text { centre in a community } \\
\text { hospital and by } \\
\text { telephone calls in } \\
\text { South Carolina. }\end{array}$ & $\begin{array}{l}\text { A nurse case manager } \\
\text { certified as a diabetes } \\
\text { educator. }\end{array}$ \\
\hline Corkery et al. [34] & $\begin{array}{l}\text { Latin American: 75\% } \\
\text { Puerto Rico, 5\% Mainland } \\
\text { U.S., 20\% Other }\end{array}$ & None. & $\begin{array}{l}\text { To explore factors that influence } \\
\text { completion of diabetes } \\
\text { education program with } \\
\text { bicultural community health } \\
\text { worker (CHW) and impact of } \\
\text { completion of this program on } \\
\text { patient knowledge, HbA1c } \\
\text { control, and patient self-care } \\
\text { practices. }\end{array}$ & RCT. & $\begin{array}{l}\text { Tertiary care teaching } \\
\text { hospital in New York } \\
\text { City, New York. }\end{array}$ & $\begin{array}{l}\text { Intervention group: } \mathrm{CHW} \text { and } \\
\text { diabetes education certified } \\
\text { nurse. Control group: } \\
\text { Diabetes education certified } \\
\text { nurse. }\end{array}$ \\
\hline Elshaw et al. [35] & 100\% Latin American & None. & $\begin{array}{l}\text { To assess the impact of culturally } \\
\text { specific, intensive diabetes } \\
\text { education program on dietary } \\
\text { patterns; To assess nutrient } \\
\text { consumption relative to the } \\
\text { Recommended Dietary } \\
\text { Allowances. }\end{array}$ & RCT. & $\begin{array}{l}\text { Church hall and health } \\
\text { clinic in Harlingen and } \\
\text { Brownsville, Texas. }\end{array}$ & $\begin{array}{l}\text { Local Mexican-American, } \\
\text { bilingual nurses with a } \\
\text { background in nutrition. }\end{array}$ \\
\hline Gary et al. [19] & $100 \%$ African American & $\begin{array}{l}\text { Precede-Proceed for } \\
\text { modification theories } \\
\text { and health } \\
\text { services research. }\end{array}$ & $\begin{array}{l}\text { To determine whether } \\
\text { multifaceted, culturally } \\
\text { sensitive, primary care-based } \\
\text { behavioral intervention } \\
\text { implemented by nurse case } \\
\text { manager (NCW) and/or } \\
\text { community health care worker } \\
\text { (CHW) could improve HbA1C } \\
\text { and diabetic control. }\end{array}$ & $\begin{array}{l}\text { Randomized Control Trial. } 4 \\
\text { groups: C (control group), } \mathrm{I}_{1} \\
\text { (NCM group), } \mathrm{I}_{2} \text { (CHW group), } \\
\text { and } \mathrm{I}_{3} \text { (NCM \& CHW group); } \\
\text { all groups receive standard } \\
\text { care. }\end{array}$ & $\begin{array}{l}\text { Physician's office, } \\
\text { clinic or by telephone } \\
\text { for NCM interventions, } \\
\text { home or telephone for } \\
\text { CHW intervention in } \\
\text { Baltimore, Maryland. }\end{array}$ & $\begin{array}{l}\text { NCM and trained } \\
\text { community-worker. }\end{array}$ \\
\hline Jaber et al. [36] & 100\% African American & $\begin{array}{l}\text { Pharmaceutical } \\
\text { Care Model. }\end{array}$ & $\begin{array}{l}\text { To assess the effectiveness of a } \\
\text { pharmaceutical care model on } \\
\text { the treatment outcome } \\
\text { measures. }\end{array}$ & (2) & $\begin{array}{l}\text { University-affiliated } \\
\text { internal medicine } \\
\text { outpatient clinic in } \\
\text { Detroit, Michigan. }\end{array}$ & Pharmacist \\
\hline $\begin{array}{l}\text { Keyserling } \\
\text { et al. [42] }\end{array}$ & 100\% African American & $\begin{array}{l}\text { Behavior Change } \\
\text { Theory. }\end{array}$ & $\begin{array}{l}\text { To determine whether a } \\
\text { culturally appropriate clinic-and } \\
\text { community-based intervention } \\
\text { will increase moderate-intensity } \\
\text { physical activity (PA). }\end{array}$ & $\begin{array}{l}\text { Randomized Trial. } 3 \text { groups: } \\
\mathrm{I}_{1} \text { (clinic \& community based } \\
\text { intervention group), } \mathrm{I}_{2} \text { (clinic } \\
\text { intervention group), and } \mathrm{I}_{3} \\
\text { (minimal intervention) }\end{array}$ & $\begin{array}{l}\text { Primary care practices, } \\
\text { including } 5 \\
\text { community health } \\
\text { centers, and the } \\
\text { general medicine clinic } \\
\text { at an academic centre } \\
\text { in Chapel Hill, North } \\
\text { Carolina. }\end{array}$ & $\begin{array}{l}\text { Dietician and trained } \\
\text { community-worker }\end{array}$ \\
\hline $\begin{array}{l}\text { Mayer-Davis } \\
\text { et al. [37] }\end{array}$ & $\begin{array}{l}\text { 82\% African American and } \\
18 \% \text { Non-Hispanic White }\end{array}$ & None. & $\begin{array}{l}\text { To develop, implement, and } \\
\text { evaluate a primary care based } \\
\text { lifestyle intervention for weight } \\
\text { management that was designed } \\
\text { to improve metabolic control. }\end{array}$ & $\begin{array}{l}\text { RCT. } 3 \text { groups: } \mathrm{I}_{1} \text { (intensive- } \\
\text { lifestyle intervention), } \mathrm{I}_{2} \\
\text { (reimbursement-lifestyle } \\
\text { intervention), and C (usual } \\
\text { care). }\end{array}$ & $\begin{array}{l}\text { Two primary health } \\
\text { care centers in South } \\
\text { Carolina. Telephone } \\
\text { calls used when } \\
\text { participants could not }\end{array}$ & Dietician \\
\hline
\end{tabular}




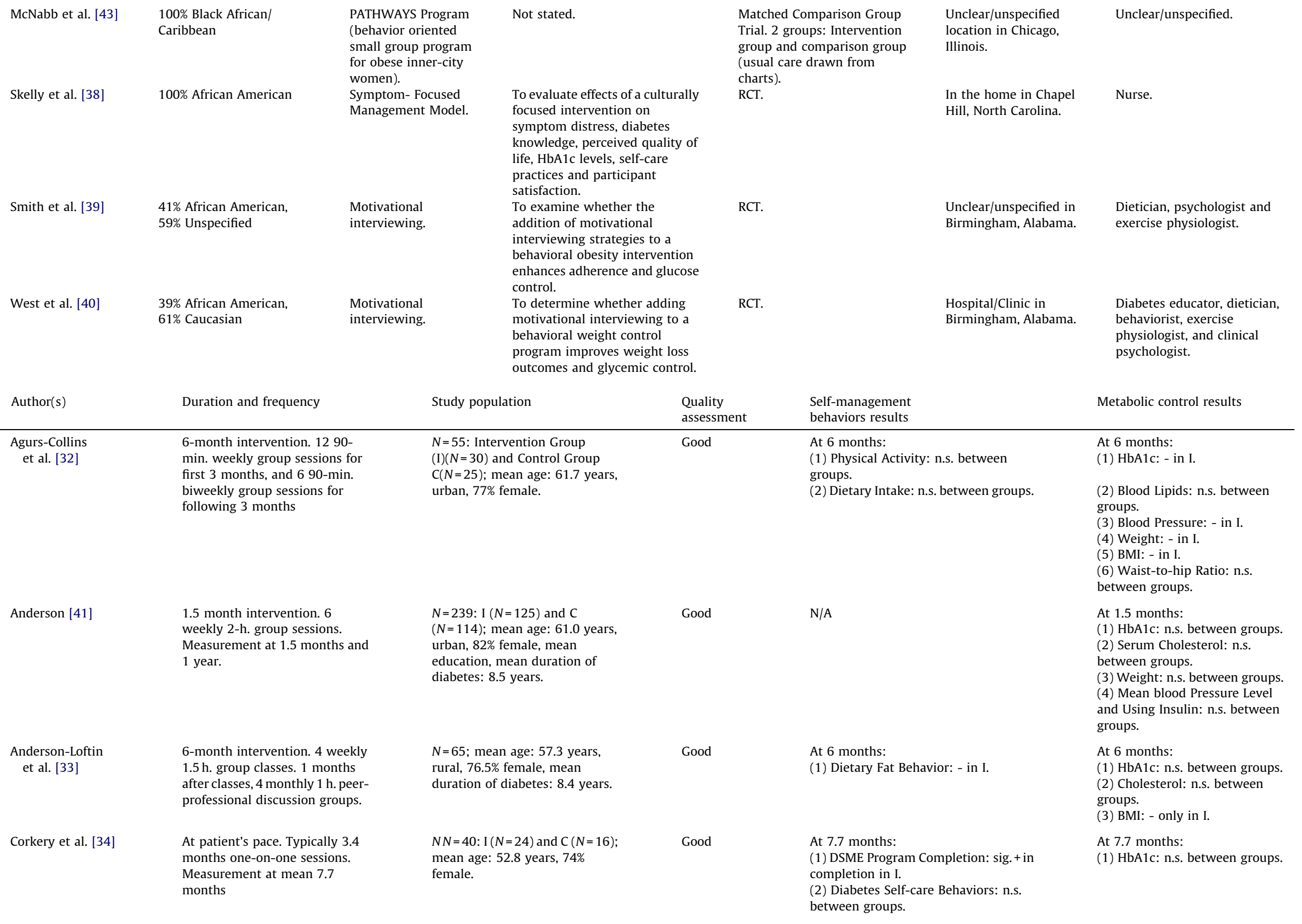




Duration and frequency

2-month intervention. $2 \mathrm{~h}$. group

weekly sessions for 8 weeks.

Measurement at 2.5 months and

3.5 months

Gary et al. [19]

24-month intervention. C: on-

going group sessions; $\mathrm{NCM}$

group $\left(I_{1}\right)$ : C plus NCM 45-min.

one-to-one visits 3 times a year;

CHW group $\left(\mathrm{I}_{2}\right)$ : C plus CHW 45 -

$60 \mathrm{~min}$. one-to-one visits 3 times

a year; $\mathrm{NCM} \& \mathrm{CHW}$ group $\left(\mathrm{I}_{3}\right)$ : $\mathrm{C}$

plus NCM $45 \mathrm{~min}$. one-to-one

visits 3 times a year and CHW 45

- 60 min. one-to-one visits 3

times year.

Jaber et al. [36]

4-month intervention. Visits from pharmacist every 2-4 weeks. Daily self-monitoring and recording of blood glucose.

\section{Keyserling}

et al. [42]

Mayer-Davis et al. [37]

12-month intervention. $161 \mathrm{~h}$.
$\mathrm{I}_{1}$ : 12-month intervention with individual counseling visits, 3

group sessions and month

intervention with individua

counseling, 2 group sessions and

monthly phone calls. $\mathrm{I}_{3}$ :

pamphlets. Measurement at 12

months (for $I_{2}$ and $I_{3}$ ).

$\mathrm{I}_{1}$ (Intensive-Lifestyle):

weekly sessions for 4 months,

biweekly for next 2 monts,

monthly for last 6 months; with

a sequential pattern of 3 group

sessions following an individual

session. $I_{2}$ (Reimbursement Life-

style): 12 -month intervention. 4

$1 \mathrm{~h}$. sessions where 3 are group

sessions and 1 is individua

session. C (Usual care): 1

individual session at the

beginning of the study.

Measurement at 6 months and

12 months

Study population

Quality

$N=104$; where men $N=31$ and

women $N=73$; mean age:

men $=62.7$ years and

women $=60.5$ years, $71 \%$ female

$N=149: C(N=25), \mathrm{I}_{1}(N=29), \mathrm{I}_{2}$

$(N=32), I_{3}(N=28)$; mean age: 59

years, urban, $76.5 \%$ female, mean

duration of diabetes: 9 years.

$N=39: C(N=22), \mathrm{I}(N=17)$; mean age: 61.6 years, urban, $69 \%$

female, mean duration of

diabetes: 6.5 years.

$N=200: I_{1}(N=67), I_{2}(N=66), I_{3}$ $(N=67)$; mean age: 59 years,

$100 \%$ female, mean duration of

diabetes: 10 years

rural, $80 \%$ female, mean duration

of diabetes: 11 years

Good

Self-management

Metabolic control results

N/A

2.5 and 3.5 months:

(1) Weight: n.s. between women

of both groups.

At 24 months:

1) Dietary Risk: n.s. between groups.

(2) Leisure-time Physical Activity

Index: n.s. between groups.
Good

12 months:

(1) Physical Activity: + in $\mathrm{I}_{1}$ and $\mathrm{I}_{2}$

(2) Dietary Outcomes: n.s. between groups.

N/A
At 24 months:

1) HbA1c: n.s. between groups

2) HDL: n.s. between groups.

(3) LDL: n.s. between groups

4) Triglycerides: n.s. between

groups.

5) Systolic Blood Pressure: n.s. between groups.

6) Diastolic Blood Pressure: n.s. between groups

(7) BMI: n.s. between groups.

At 4 months:

1) Glycosolated Hemoglobin: in I.

(2) Fasting Plasma Glucose: - in I. (3) Blood Pressure, Lipid Profile, Renal Parameter, and Weight:

n.s. between groups.

At 12 months:

(1) Glycosolated Hemoglobin:

n.s. between groups.

(2) Weight, Total and HDL

Cholesterol: n.s. between groups.

At 6 months:

(1)

(2) Lipid Profile, Blood Pressure:

n.s. between groups.

(3) BMI: - compared to C

(4) Weight: - in $I_{1}$

1) Weight: n.s. between groups 


\subsection{Anthropometrics}

Eleven studies [19,32,33,35-37,39-43] reported anthropometrics outcomes; three of these $[32,33,43]$ obtained positive effects. Seventeen of the 38 intervention features were associated with a positive success rate difference (see Table 2 ).

\subsection{Physical activity}

Five studies [19,32,38,39,42] reported on physical activity; only one [42] had a positive effect. Thirty-four intervention features were included in the analysis, of which 12 were associated with a positive success rate difference (see Table 2 ).

\subsection{Diet}

Six studies [19,32,33,35,38,42] reported on dietary outcomes; two $[33,38]$ had positive effects. Thirty-six intervention features were included in the analysis, of which 11 were associated with a positive rate difference (see Table 2 ).

Refer to the online supplemental data for more information on percent success rate differences (Table 3 ) and analysis of features within each individual outcome (Tables 4-7).

\section{Discussion and conclusion}

\subsection{Discussion}

DSME programs are complex interventions with various content and delivery components necessary for the education and skills building required for diabetes self-management. However, limited efforts have been made to investigate which intervention features are associated with a positive outcome, specifically for women of diverse ethnic backgrounds. Studies mainly concentrated on glycemic control (i.e., HbA1c levels) (10 studies) or anthropometric outcomes (11 studies), as opposed to behavioral outcomes such as diet ( 5 studies) and physical activity (5 studies). Since behavioral outcomes strongly reflect the lifestyle changes needed to achieve the desirable metabolic outcomes $[18,44]$, it is imperative to understand how intervention features affect these intermediary outcomes as well.

Only five (of 38) intervention features had positive success rate differences for at least three of the outcomes examined in this review: hospital-based intervention setting; group intervention format; situational problem-solving; high intensity (10 or more intervention sessions); and incorporating dietitians as interventionists.

Because of their broad influence, we recommend the features that demonstrate success across multiple outcomes in DSME programming for the populations of interest. Many of these features are also recommended in DSME programming for the general population by the American Diabetes Association (ADA) and the Canadian Diabetes Association (CDA). Specifically, group programming and situational problem-solving are recommended by both national organizations [45,45], as these features are shown to be effective in improving HbA1c outcomes [46]. Furthermore, the CDA recommends nutritional counseling of clients with diabetes by a dietitian, either one-on-one or in small group settings, to lower HbA1c levels [45]. A recent study supports this recommendation; it found that visits by a dietitian are associated with lower hospitalization rates and charges in persons of varied cultural backgrounds compared to diabetes classes and one-on-one visits from non-dietitian health professionals [47]. Our analysis suggests that incorporating dietitians has positive success rate differences on anthropometrics, and physical activity, in addition to HbA1c. 
Table 2

Positive success rate differences (\%) in HbA1c, anthropometrics, physical activity, and diet outcomes ( $N=13$ studies).

\begin{tabular}{|c|c|c|c|c|}
\hline \multirow[t]{2}{*}{ Feature } & \multicolumn{4}{|l|}{ Outcome } \\
\hline & Diet & Anthropometrics & Physical activity & HbA1c \\
\hline \multicolumn{5}{|l|}{ Intervention setting } \\
\hline $\begin{array}{l}\text { Community-based: delivered within the participants' community (e.g., community } \\
\text { center, YMCA) }(n=3)\end{array}$ & & & $100^{\mathrm{a}}$ & \\
\hline Home-based: delivered in the home $(n=4)$ & $66.67^{\mathrm{a}}$ & $16.67^{\mathrm{a}}$ & & \\
\hline $\begin{array}{l}\text { Hospital-based: delivered in a clinic affiliated with a hospital (e.g., outpatient } \\
\text { ambulatory clinic) }(n=8)\end{array}$ & & 28.57 & $50^{\mathrm{a}}$ & 33.33 \\
\hline \multicolumn{5}{|l|}{ Primary care-based: delivered in a primary care setting (e.g. physician's office) $(n=1)$} \\
\hline \multicolumn{5}{|l|}{ Intervention format } \\
\hline $\begin{array}{l}\text { One-on-one: intervention is delivered individually to the participant by the } \\
\text { interventionist }(n=11)\end{array}$ & 40 & & $\mathrm{~N} / \mathrm{A}$ & $\mathrm{N} / \mathrm{A}$ \\
\hline Group: intervention is delivered to a group $(n=9)$ & & 33.33 & $33.33^{\mathrm{a}}$ & 8.33 \\
\hline \multicolumn{5}{|l|}{ Mode of delivery } \\
\hline Face-to-face: Intervention is delivered face-to-face with patients $(n=13)$ & $\mathrm{N} / \mathrm{A}$ & $\mathrm{N} / \mathrm{A}$ & $\mathrm{N} / \mathrm{A}$ & $\mathrm{N} / \mathrm{A}$ \\
\hline $\begin{array}{l}\text { Written Literature: Intervention uses written material to deliver knowledge } \\
\text { (e.g., handbook) }(n=4)\end{array}$ & & $35.71^{\mathrm{a}}$ & & $25^{\mathrm{a}}$ \\
\hline Telephone: Intervention is delivered by phone $(n=4)$ & & & $50^{\mathrm{a}}$ & \\
\hline Audio-Visual: Intervention uses educational videos to deliver knowledge $(n=1)$ & & & Not present & Not present \\
\hline \multicolumn{5}{|l|}{ Education strategies } \\
\hline Didactic: intervention uses a unidirectional lecture-based teaching strategy $(n=9)$ & & 3.57 & & 50 \\
\hline $\begin{array}{l}\text { Goal-Setting Dictated: intervention has a fixed goal for participants to achieve as } \\
\text { determined by the intervention }(n=9)\end{array}$ & & & $25^{\mathrm{a}}$ & 50 \\
\hline $\begin{array}{l}\text { Goal-Setting Negotiated: intervention has a mutually-agreed goal by the participant } \\
\text { and interventionist }(n=9)\end{array}$ & $50^{\mathrm{a}}$ & & $25^{\mathrm{a}}$ & \\
\hline $\begin{array}{l}\text { Situational Problem-Solving: intervention is aimed at increasing participants' } \\
\text { problem-solving ability related to their diabetes management }(n=9)\end{array}$ & $50^{\mathrm{a}}$ & 37.50 & $25^{\mathrm{a}}$ & \\
\hline $\begin{array}{l}\text { Peer-led Discussion: participants initiate diabetes-related topics/components they } \\
\text { want to focus on during group sessions }(n=1)\end{array}$ & Not present & & Not present & \\
\hline $\begin{array}{l}\text { Interactive Discussion Groups: participants discuss and/or share content in a group } \\
\text { setting, facilitated by an interventionist }(n=5)\end{array}$ & & 60 & & $4.76^{\mathrm{a}}$ \\
\hline $\begin{array}{l}\text { Feedback: interventionists provide specific feedback for participant } s \text { to aid in } \\
\text { monitoring aspects of their own management (e.g. diet and exercise feedback) } \\
(n=5)\end{array}$ & & & & 60 \\
\hline $\begin{array}{l}\text { Diaries and Reports: a specific type of feedback activity, where food diaries, } \\
\text { physical activity logs, and SMBG logs were used by participants to record } \\
\text { specific intervention components }(n=4)\end{array}$ & & & & $75^{\mathrm{a}}$ \\
\hline \multicolumn{5}{|l|}{ Duration } \\
\hline Short Duration: length of intervention is $<6$ months $(n=7)$ & $25^{\mathrm{a}}$ & & & 20 \\
\hline Long Duration: length of intervention is $\geq 6$ months $(n=6)$ & & 13.33 & $33.33^{\mathrm{a}}$ & \\
\hline \multicolumn{5}{|l|}{ Intensity } \\
\hline Low Intensity: participant participates in less than 10 intervention sessions $(n=7)$ & $50^{\mathrm{a}}$ & & & \\
\hline $\begin{array}{l}\text { High Intensity: participant participates in equal or more than } 10 \text { intervention } \\
\text { sessions }(n=6)\end{array}$ & & 13.33 & $33.33^{\mathrm{a}}$ & $33.33^{\mathrm{a}}$ \\
\hline \multicolumn{5}{|l|}{ Interventionist } \\
\hline Nurse: intervention delivered by nurse $(n=5)$ & $50^{\mathrm{a}}$ & $8.33^{\mathrm{a}}$ & & \\
\hline Dietitians: intervention delivered by dietitian $(n=7)$ & & 28.57 & $33.33^{\mathrm{a}}$ & 8.33 \\
\hline Community Peer Worker: intervention delivered by community peer worker $(n=3)$ & & & $50^{\mathrm{a}}$ & \\
\hline $\begin{array}{l}\text { Multidisciplinary Team: intervention is delivered by two or more types of } \\
\text { interventionists }(n=7)\end{array}$ & & 28.57 & $25^{\mathrm{a}}$ & \\
\hline \multicolumn{5}{|l|}{ Content/specific components of intervention } \\
\hline Psychosocial: intervention taught psychosocial related content $(n=3)$ & $80^{\mathrm{a}}$ & & & \\
\hline Diet: intervention taught diet related content $(n=11)$ & $\mathrm{N} / \mathrm{A}$ & 30 & $\mathrm{~N} / \mathrm{A}$ & 37.50 \\
\hline Exercise: intervention taught exercise related content $(n=9)$ & & & $\mathrm{N} / \mathrm{A}$ & 42.86 \\
\hline SMBG: intervention taught self-management of blood glucose (SMBG) content $(n=5)$ & $25^{\mathrm{a}}$ & & & $30^{\mathrm{a}}$ \\
\hline Medication Adherence: intervention encouraged medication adherence $(n=3)$ & $25^{\mathrm{a}}$ & & & \\
\hline $\begin{array}{l}\text { Recognition of Complications: intervention taught recognition of diabetes related } \\
\text { complications }(n=3)\end{array}$ & & & Not present & $21.43^{\mathrm{a}}$ \\
\hline \multicolumn{5}{|l|}{ Foot care: intervention taught foot care related content $(n=4)$} \\
\hline $\begin{array}{l}\text { Supervised Exercise: patients participate in physical activity as part of the intervention } \\
\text { sessions }(n=1)\end{array}$ & & $80^{\mathrm{a}}$ & & $75^{\mathrm{a}}$ \\
\hline \multicolumn{5}{|l|}{ Intervention design } \\
\hline $\begin{array}{l}\text { Language Tailoring: intervention included interventionists, discussions, materials or } \\
\text { resources in the target dialect/language }(n=4)\end{array}$ & & $54.17^{\mathrm{a}}$ & & $4.76^{\mathrm{a}}$ \\
\hline $\begin{array}{l}\text { Cultural Tailoring: intervention included interventionists, recipes, beliefs, values that } \\
\text { belongs to target culture of interest }(n=8)\end{array}$ & $50^{\mathrm{a}}$ & 50 & & \\
\hline $\begin{array}{l}\text { Needs Assessment: assesses each participant's individual needs formally for designing } \\
\text { the content of the intervention before or during the initial sessions }(n=6)\end{array}$ & & $35.71^{\mathrm{a}}$ & $33.33^{\mathrm{a}}$ & \\
\hline $\begin{array}{l}\text { Individualized Assessment: assesses each participant's individual need throughout } \\
\text { the intervention for tailoring the content of the intervention throughout the } \\
\text { intervention (i.e., patient-centered care) }(n=2)\end{array}$ & Not present & & Not present & $25^{\mathrm{a}}$ \\
\hline
\end{tabular}

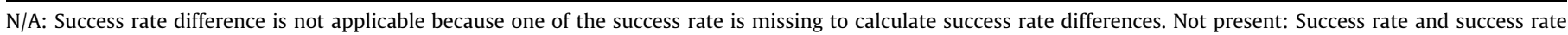
differences are not present because feature is not present for that specific outcome. Empty cells indicate negative success rate differences.

a Success rate difference is based on less than 5 studies so interpretation should be cautioned. 
We are unsure why hospital-based interventions appear more successful across outcomes. However, hospital-based settings are more likely to have high-intensity sessions, in our review, which was found to be more successful on HbA1c, anthropometric, and physical activity. There is some evidence to suggest that high-intensity interventions or greater patient-provider contact hours is an important DSME feature that positively affects glycemic control [31,44]. Also, hospital-based interventions (eight studies) have been studied more than community (three studies) or home (four studies) based interventions. As the current trend in North America is to move DSME into community settings, understanding how this feature affects certain outcomes is imperative.

Tailoring DSME is suggested to improve diabetes-related outcomes [46]. Providing evidence on intervention features that have a high rate difference for the specific outcome of interest can facilitate tailoring (see Table 2). To illustrate, incorporating peer workers as interventionists and using the telephone as a means of delivering education had a positive rate difference of $50 \%$ for physical activity. Community peer workers are reported to be important interventionists for women in ethnic minorities, as they often provide social support and act as a liaison between the participants and health care professionals [48,49]. The use of telephone for improving physical activity is supported by a metaanalysis that reported delivery of diabetes self-management coaching via telephone had a positive effect on exercise [45]. Phone contact is convenient, simple and inexpensive; it may also be useful in reaching individuals who have barriers traveling to programs.

Interventions that have psychosocial content (e.g., discuss quality of life with participants, and include empowerment or motivational interviewing) had a positive rate difference of $80 \%$ with diet outcomes. The relationship between diet and psychosocial issues is particularly relevant for women from high-risk ethnic groups living with DM. Interventions that focus on psychosocial support and self-management have proved successful in some studies among Hispanic populations because they address emotions and beliefs about diabetes and deal with the question of how adjusting one's lifestyle may conflict with cultural norms [50]. Another study suggests that African American women have difficulty complying with diet because of poor psychosocial adjustment and denial of the severity of the disease [51] and thus, DSME programming that incorporates psychosocial coping strategies may be effective in improving dietary behaviors.

Using diaries and providing feedback to participants both have over $50 \%$ positive rate differences for HbA1c outcomes in our findings. Providing feedback and using diaries or logs may be useful in improving HbA1c because they are tools that may allow interventionists and patients to discuss barriers and find solutions to overcome self-management challenges. In a randomized trial, a graphical representation of HbA1c level for patients and physicians to use as a log and point of feedback for every visit has been found to decrease HbA1c levels in inner-city patients compared to those who did not use the logs [52]. This feature may be effective because it facilitates communication and overcomes some language, culture and literacy barriers due to its graphic nature [52].

As mentioned earlier, DSME interventions have proven to be generally effective; however, the proportion of intervention studies that report positive effects for HbA1c, anthropometrics, physical activity, and diet was less than one-third in our review. Perhaps the features used in these interventions are somewhat traditional that worked well in mainstream population, which may not benefit women from high-risk ethnic groups living with DM. For instance, intervention features that address broader community issues (e.g., cultural group cohesion and social support) may be more beneficial on outcomes than the more traditional features (e.g., written educational resources, didactic teaching styles). Cultural appropriateness of an intervention is advanced when "surface structures" such as language tailoring of brochures is supplemented with "deep structures" such as addressing cultural history, values, and norms [53]. Intervention data available for this review largely focuses on these aforementioned "surface structures" and only some data were available on "deep structure" features (i.e., individualized assessment, needs assessment, cultural tailoring). Future research needs to assess the effectiveness of both surface and deeper structures within DSME programming for women from high-risk ethnic groups living with DM.

Research on gender differences within ethno-cultural populations is important given the potential impact of gender roles, cultural norms, beliefs and values on women and their health management. We advocate that future program evaluations include a gender-based analysis, which will provide valuable information to better tailor and deliver services to a growing population of individuals at greater risk for diabetes and its complications.

The heterogeneity in study populations, interventions, and measurements of health outcomes limited our ability to conduct a meta-analysis. Thus our calculation is based on rate differences and not the effect size. The handful of studies $(n=13)$ that fit our criteria limited our ability to stratify our analysis by cultural group. Generally, searching for gender-specific information was challenging, as most DSME interventions are delivered and evaluated for both men and women without a gender-based analysis or stratification. We acknowledge that the populations we aggregated have different cultural values, beliefs, and experiences. However, these groups of women living with diabetes may have some parallel self-management experiences, given that they may share social similarities because of their gender and ethno-cultural experiences, which may influence the self-management processes. Given the small number of studies, our conclusions about the success of various intervention features should be interpreted with caution.

\subsection{Conclusion}

Although the provision of DSME is pervasive and is recommended as a critical resource to assist and support diabetes selfmanagement among individuals, we have little understanding of intervention features that promote behavior change and in turn improve clinical outcomes, particularly in ethnically diverse populations. This comprehensive review provides insight into how DSME interventions can be made more effective by placing emphasis on intervention features that are potentially successful at achieving specific outcomes in women of African/Caribbean and Hispanic/Latin ethnicity. While five intervention features (i.e., hospital-based intervention setting; group intervention format; situational problem-solving; frequent sessions; or incorporating dietitians as interventionists) have a positive and broad impact on three out of the four outcomes assessed, other features also have a strong positive effect on specific outcomes that should be considered.

\subsection{Practical implications}

Given the results from our systematic literature review, we propose that the balance between tailoring care and optimizing resources can be achieved by prioritizing common intervention features that have a positive yet broad effect on outcomes, and then tailoring intervention features based on patients' personal 
goals or specific health outcomes of interest. This would allow additional flexibility in how DSME interventions are delivered and personalized. Selecting intervention features that are most suitable for an individual is a more patient-centered approach in delivering DSME.

\section{Funding}

Centre for Urban Health Initiatives: Canadian Health Research Institute, Institute of Population and Public Health; Faculty of Community Services, Seed Grant Ryerson University.

\section{Conflict of interest}

The authors of this review have no relevant conflict of interests to disclose.

\section{Appendix A. Supplementary data}

Supplementary data associated with this article can be found, in the online version, at http://dx.doi.org/10.1016/j.pec.2013.03.007.

\section{References}

[1] Shaw JE, Sicree RA, Zimmet PZ. Global estimates of the prevalence of diabetes for 2010 and 2030. Diabetes Res Clin Pract 2010;87:4-14.

[2] National Institute of Diabetes and Digestive and Kidney Diseases. National Diabetes Statistics, 2007 fact sheet. 2008.

[3] Shah BR. Utilization of physician services for diabetic patients from ethnic minorities. J Public Health (Oxf) 2008;30:327-31.

[4] Creatore MI, Moineddin R, Booth G, Manuel DH, DesMeules M, McDermott S, et al. Age- and sex-related prevalence of diabetes mellitus among immigrants to Ontario, Canada. Can Med Assoc J 2010;182:781-9.

[5] Harris MI. Racial and ethnic differences in health insurance coverage for adults with diabetes. Diabetes Care 1999;22:1679-82.

[6] Wei M, Gaskill SP, Haffner SM, Stern MP. Effects of diabetes and level of glycemia on all-cause and cardiovascular mortality. The San Antonio Heart Study. Diabetes Care 1998;21:1167-72.

[7] Carter JS, Pugh JA, Monterrosa A. Non-insulin-dependent diabetes mellitus in minorities in the United States. Ann Intern Med 1996;125:221-32.

[8] Umpierrez GE, Gonzalez A, Umpierrez D, Pimentel D. Diabetes mellitus in the Hispanic/Latino population: an increasing health care challenge in the United States. Am J Med Sci 2007;334:274-82.

[9] Barrett-Connor E, Giardina EG, Gitt AK, Gudat U, Steinberg HO, Tschoepe D. Women and heart disease: the role of diabetes and hyperglycemia. Arch Intern Med 2004;164:934-42.

[10] Zandbergen AA, Sijbrands EJ, Lamberts SW, Bootsma AH. Normotensive women with type 2 diabetes and microalbuminuria are at high risk for macrovascular disease. Diabetes Care 2006;29:1851-5.

[11] Huxley R, Barzi F, Woodward M. Excess risk of fatal coronary heart disease associated with diabetes in men and women: meta-analysis of 37 prospective cohort studies. Brit Med J 2006;332:73-8.

[12] Liao Y, Cooper RS, Ghali JK, Lansky D, Cao G, Lee J. Sex differences in the impact of coexistent diabetes on survival in patients with coronary heart disease. Diabetes Care 1993;16:708-13.

[13] Tuomilehto J, Rastenyte D, Jousilahti P, Sarti C, Vartiainen E. Diabetes mellitus as a risk factor for death from stroke. Prospective study of the middle-aged Finnish population. Stroke 1996;27:210-5.

[14] Anderson RJ, Freedland KE, Clouse RE, Lustman PJ. The prevalence of comorbid depression in adults with diabetes: a meta-analysis. Diabetes Care 2001;24: 1069-78.

[15] Grigsby AB, Anderson RJ, Freedland KE, Clouse RE, Lustman PJ. Prevalence of anxiety in adults with diabetes: a systematic review. J Psychosom Res 2002;53:1053-60.

[16] Delamater AM, Jacobson AM, Anderson B, Cox D, Fisher L, Lustman P, et al. Psychosocial therapies in diabetes: report of the Psychosocial Therapies Working Group. Diabetes Care 2001;24:1286-92.

[17] Clouse RE, Lustman PJ, Freedland KE, Griffith LS, McGill JB, Carney RM. Depression and coronary heart disease in women with diabetes. Psychosom Med 2003;65:376-83.

[18] Ellis SE, Speroff T, Dittus RS, Brown A, Pichert JW, Elasy TA. Diabetes patient education: a meta-analysis and meta-regression. Patient Educ Couns 2004; 52:97-105.

[19] Gary TL, Bone LR, Hill MN, Levine DM, McGuire M, Saudek C, et al. Randomized controlled trial of the effects of nurse case manager and community health worker interventions on risk factors for diabetes-related complications in urban African Americans. Prev Med 2003;37:23-32.
[20] Norris SL, Engelgau MM, Narayan KM. Effectiveness of self-management training in type 2 diabetes: a systematic review of randomized controlled trials. Diabetes Care 2001;24:561-87.

[21] Norris SL, Nichols PJ, Caspersen CJ, Glasgow RE, Engelgau MM, Jack L, et al. Increasing diabetes self-management education in community settings. A systematic review. Am J Prev Med 2002;22:39-66.

[22] Pimouguet C, Le GM, Thiebaut R, Dartigues JF, Helmer C. Effectiveness of disease-management programs for improving diabetes care: a meta-analysis. CMAJ 2011;183:E115-27.

[23] Li R, Zhang P, Barker LE, Chowdhury FM, Zhang X. Cost-effectiveness of interventions to prevent and control diabetes mellitus: a systematic review. Diabetes Care 2010;33:1872-94.

[24] Blue CL, Black DR. Synthesis of intervention research to modify physical activity and dietary behaviors. Res Theory Nurs Pract 2005;19:25-61.

[25] Brown SA, Harrist RB, Villagomez ET, Segura M, Barton SA, Hanis CL. Gender and treatment differences in knowledge, health beliefs, and metabolic control in Mexican Americans with type 2 diabetes. Diabetes Educ 2000;26:425-38.

[26] Stone M, Pound E, Pancholi A, Farooqi A, Khunti K. Empowering patients with diabetes: a qualitative primary care study focusing on South Asians in Leicester, UK. Fam Pract 2005;22:647-52.

[27] Zaza S, Wright-De Aguero LK, Briss PA, Truman BI, Hopkins DP, Hennessy MH, et al. Data collection instrument and procedure for systematic reviews in the Guide to Community Preventive Services. Task Force on Community Preventive Services. Am J Prev Med 2000;18:44-74.

[28] Elasy TA, Ellis SE, Brown A, Pichert JW. A taxonomy for diabetes educational interventions. Patient Educ Couns 2001;43:121-7.

[29] Hawker S, Payne S, Kerr C, Hardey M, Powell J. Appraising the evidence: reviewing disparate data systematically. Qual Health Res 2002;12:1284-99.

[30] National Collaborating Centre for Methods and Tools. Quality assessment tool for quantitative studies. Hamilton, Ontario: McMaster University; 2008, 14-42012. Ref Type: Online Source.

[31] Glazier RH, Bajcar J, Kennie NR, Willson K. A systematic review of interventions to improve diabetes care in socially disadvantaged populations. Diabetes Care 2006;29:1675-88.

[32] Agurs-Collins TD, Kumanyika SK, Ten Have TR, Adams-Campbell LL. A randomized controlled trial of weight reduction and exercise for diabetes management in older African-American subjects. Diabetes Care 1997;20:1503-11.

[33] Anderson-Loftin W, Barnett S, Bunn P, Sullivan P, Hussey J, Tavakoli A. Soul food light: culturally competent diabetes education. Diabetes Educ 2005; 31:555-63.

[34] Corkery E, Palmer C, Foley ME, Schechter CB, Frisher L, Roman SH. Effect of a bicultural community health worker on completion of diabetes education in a Hispanic population. Diabetes Care 1997;20:254-7.

[35] Elshaw EB, Young EA, Saunders MJ, McGurn WC, Lopez LC. Utilizing a 24-hour dietary recall and culturally specific diabetes education in Mexican Americans with diabetes. Diabetes Educ 1994;20:228-35.

[36] Jaber LA, Halapy H, Fernet M, Tummalapalli S, Diwakaran H. Evaluation of a pharmaceutical care model on diabetes management. Ann Pharmacother 1996;30:238-43.

[37] Mayer-Davis EJ, D’Antonio AM, Smith SM, Kirkner G, Levin MS, Parra-Medina $D$, et al. Pounds off with empowerment (POWER): a clinical trial of weight management strategies for black and white adults with diabetes who live in medically underserved rural communities. Am J Public Health 2004;94: 1736-42.

[38] Skelly AH, Carlson JR, Leeman J, Holditch-Davis D, Soward AC. Symptomfocused management for African American women with Type 2 diabetes: a pilot study. Appl Nurs Res 2005; 18:213-20.

[39] Smith DE, Heckemeyer CM, Kratt PP, Mason DA. Motivational interviewing to improve adherence to a behavioral weight-control program for older obese women with NIDDM. A pilot study. Diabetes Care 1997;20:52-4.

[40] West DS, DiLillo V, Bursac Z, Gore SA, Greene PG. Motivational interviewing improves weight loss in women with type 2 diabetes. Diabetes Care 2007; 30:1081-7.

[41] Anderson RM, Funnell MM, Arnold MS, Barr PA, Edwards GJ, Fitzgerald JT. Assessing the cultural relevance of an education program for urban African Americans with diabetes. Diabetes Educ 2000;26:280-9.

[42] Keyserling TC, Samuel-Hodge CD, Ammerman AS, Ainsworth BE, HenriquezRoldan CF, Elasy TA, et al. A randomized trial of an intervention to improve self-care behaviors of African-American women with type 2 diabetes: impact on physical activity. Diabetes Care 2002;25:1576-83.

[43] McNabb WL, Quinn MT, Rosing L. Weight loss program for inner-city black women with non-insulin-dependent diabetes mellitus: pathways. J Am Diet Assoc 1993;93:75-7.

[44] Fan L, Sidani S. Effectiveness of diabetes self-management education intervention elements: a meta-analysis. Canadian Journal of Diabetes 2009;33:18-26.

[45] Canadian Diabetes Association Clinical Guidelines Expert Committee. Canadian Diabetes Association 2008 Clinical Practice Guidelines for the Prevention and Management of Diabetes in Canada. Canadian Journal of Diabetes 32 [Supplement 1]: Canadian Diabetes Association; 2008. Report No.: 7-5-0011.

[46] Funnell MM, Brown TL, Childs BP, Haas LB, Hosey GM, Jensen B, et al. National standards for diabetes self-management education. Diabetes Care 2008; 31:S97-104.

[47] Robbins JM, Thatcher GE, Webb DA, Valdmanis VG. Nutritionist visits, diabetes classes, and hospitalization rates and charges: the Urban Diabetes Study. Diabetes Care 2008;31:655-60. 
[48] Norris SL, Chowdhury FM, Van LK, Horsley T, Brownstein JN, Zhang X, et al. Effectiveness of community health workers in the care of persons with diabetes. Diabet Med 2006;23:544-56.

[49] Andrews JO, Felton G, Wewers ME, Heath J. Use of community health workers in research with ethnic minority women. J Nurs Scholarsh 2004;36:358-65.

[50] Caban A, Walker EA. A systematic review of research on culturally relevant issues for Hispanics with diabetes. Diabetes Educ 2006;32: 584-95.
[51] Amoako E, Skelly AH, Rossen EK. Outcomes of an intervention to reduce uncertainty among African American women with diabetes. West J Nurs Res 2008;30:928-42.

[52] Chapin RB, Williams DC, Adair RF. Diabetes control improved when inner-city patients received graphic feedback about glycosylated hemoglobin levels. J Gen Intern Med 2003;18:120-4.

[53] Jack Jr L, Liburd L, Spencer T, Airhihenbuwa CO. Understanding the environmental issues in diabetes self-management education research: a reexamination of 8 studies in community-based settings. Ann Intern Med 2004;140:964-71. 